\title{
EFSUMB-Online-Kurs mit 2 EFSUMB-Credits
}

Aufgrund der aktuellen Pandemie mussten etliche Sonoanatomiekurse und praktische muskuloskelettale Ultraschallkurse im Inund Ausland abgesagt werden. Erfreulicherweise konnte der 15. Ultraschalltag (US-Day, SONODAY) virtuell abgehalten werden. Die Teilnehmer konnten die Vorträge von Stefano Bianchi und Giorgio Tamborrini auf einer DVD anschauen, danach das gedruckte Handout und eine frei zugängliche Publikation (https://econtent. hogrefe.com/doi/pdf/10.1024/1661-8157/ a003435) studieren. Im Anschluss beantworteten die Teilnehmer über 80 CMEFragen online zum Erwerb der SGUM-, SGR-, SSIPM- und EFSUMB-Credits.

In einer verkürzten Form bieten wir nun nach Rücksprache mit der EFSUMB einen angepassten Online-Kurs in Englisch an, mit der Möglichkeit des Erwerbs von 2 EFSUMB-Credits (1. Video-Vorlesung on-

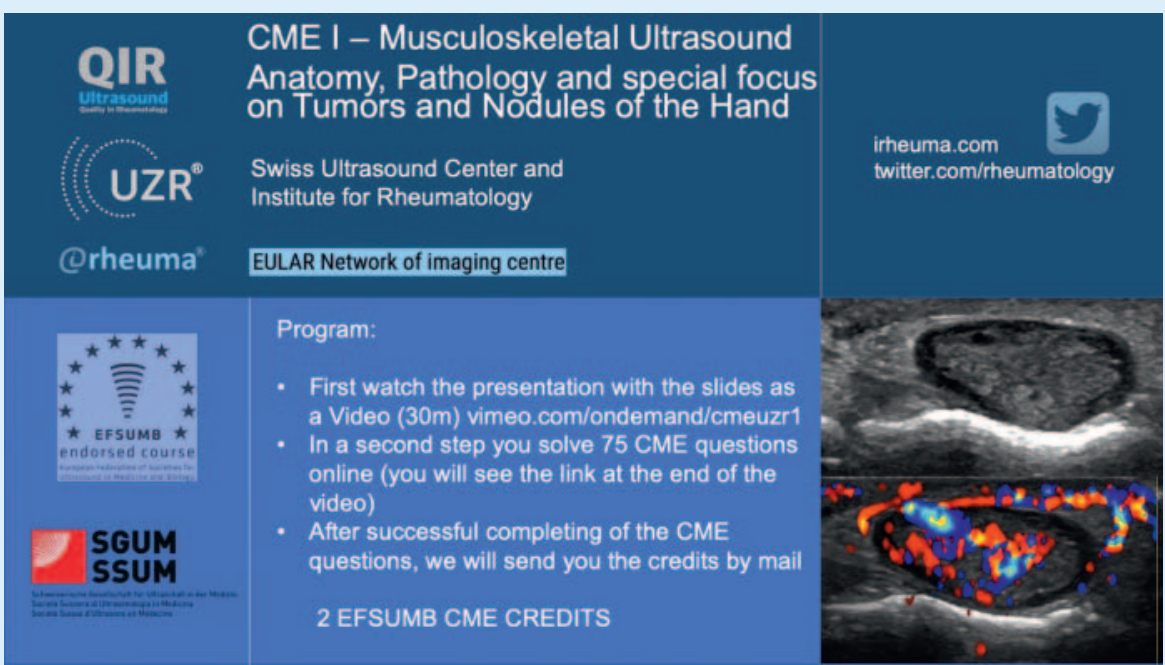

line, 2. 75 CME-Fragen). Details finden Sie unter https://twitter.com/Rheumatology/ status/1276843768705097729?s=20 oder ZR-Video-Plattform, wo Sie über 250 Lehrvideos zum muskuloskelettalen Ultraschall finden. 